\title{
"Here comes the sun": Evidence of the Effect of Sun on Compliance to a Survey Request
}

\author{
Nicolas Guéguen', Céline Jacob ${ }^{1}$ \\ 1 Université de Bretagne-Sud \\ Keywords: compliance, survey request, sun, weather \\ https://doi.org/10.29115/SP-2014-0025
}

Survey Practice

Vol. 7, Issue 5, 2014

\begin{abstract}
Literature had reported that pleasant weather conditions influenced positive social relationships and improved moods. However the direct effect of sun on compliance to a request still remains in question. Male and female passersby were asked in a street to participate in a survey. The experiment was conducted on predominantly cloudy or predominantly sunny days, but precaution was taken to control for the temperature and not to solicit participants when it rained. Passersby complied more favorably with the survey request on the sunnier days. Positive mood induced by sun may explain such results.
\end{abstract}

\section{Survey Request}

Several experimental studies have shown that decisions are positively affected by weather. Hirshleifer and Shumway (2003) reported that sunshine level was positively correlated with returns in the stock-market. Simonsohn (2007) found that applicants' academic attributes are weighted more heavily on university admission decisions on cloudier days while non-academic attributes are weighted more heavily on sunnier days.

Prior research has also shown that human social relationships are influenced by weather conditions. Cunningham (1979, study 2) found outdoor sunshine levels were significantly related to the gratuity left by restaurant customers. However, Flynn and Greenberg (2010) using a very large sample size (11,766 observations and 130 in Cunningham's study) failed to observe a weather effect on tipping. Rind (1996) has conducted an experiment in a hotel in rooms that did not have windows. A male server who delivered food and drinks to guests' rooms reported to guests the sky conditions (sunny, partly sunny, cloudy, or rainy). It was found that more tips were left when the server mentioned pleasant weather condition. In a similar study, Rind and Strohmetz (2001) found that servers received more tips when they wrote a note on the back of customers' checks noting the weather would be good the next day.

To explain this relation between weather conditions and human behavior, scientists argue that sunshine activated positive emotions and mood which influence subsequent behavior (Cunningham 1979; Denissen et al. 2008; Keller et al. 2005) and several studies reported that positive mood facilitated social relationships and helping behavior (Bizman et al. 1980; Forgas 1997, 1998; Harris and Smith 1975; Job 1987; Rind 1997; Weyant 1978). 
Overall, these studies seem to show that variation in sunshine is associated with variation in human behavior. The objective of this study was to test the effect of weather conditions on compliance to a survey request. Cunningham (1979) found that participants approached by an interviewer to participate in a survey were less reluctant to comply on sunnier days compared to cloudier days. However, in Cunningham's (1979) study possible confounds variables could explain the results found. The temperature ranged from $-18^{\circ} \mathrm{C}$ to $38^{\circ} \mathrm{C}$, and participants were approached during two different seasons: spring and winter. The solicitors were not blind about the hypothesis. Thus, in order to assure results were not driven by temperature rather than relatively sunshine levels, we conducted an experiment where people in the street were solicited to participate in a survey. Depending on the case, the participants were solicited on sunnier days or on cloudier days. It was hypothesized that participants solicited would be more inclined to comply with the request on sunnier days.

\section{Method}

\section{Participants}

The participants come from a convenience sample where 616 men and 768 women (between the age of approximately 25 and 50) were asked to respond to a survey while they were walking alone in pedestrian areas of two towns (between 60-70,000 inhabitants) situated on the south coast of Brittany in France.

\section{Procedure}

The experiment was conducted as a part of survey sponsored by a local newspaper about the perceptions of the newspaper in the population. Interviews were undergraduate business students. The experiment was presented as a field exercise at the end of the survey course the students have received during one semester of their university year. Each interviewer conducted a pretest survey with 6 participants ( 3 males and 3 females) in order to be familiar with the approach, the procedure, and the questions in the survey.

Eight young women $(M=20.6$ years, $S D=1.2)$ and six young men $(M=20.7$ years, $\mathrm{SD}=1.4$ ) served as interviewers in this study. The clothing appearance of each of the interviewers was nearly identical: black trousers and a black long sleeved tee-shirt worn under a white tee-shirt. To avoid possible variations in the interviewers' behavior according to the experimental conditions, the interviewers were not informed about the experimental hypothesis.

The interviewer stationed himself/herself in front of a store and chose a participant walking in her direction. The interviewer approached a participant after counting the passage of 2 pedestrians in his or her zone. If a child, an adolescent, an older person, or a group of people passed, the interviewer waited until a person corresponding to the profile (men or women of roughly 25 to 50 years of age walking alone) walked by. The interviewer made contact by 
saying: "Excuse me sir/madam. We are currently conducting a survey on the perception of a local newspaper. Would you agree to answer the questionnaire that will take 3-4 minutes?" Participants who refused were thanked. Those who complied then immediately responded to the interview and were thanked at the end. To prevent possible multiple solicitations of the same pedestrian, the study was conducted at the same time in each town by different interviewers and a minimal distance of one kilometer was used between each interviewer. By this way, it was not possible with the distance to solicit the same participant at the same moment. Each interviewer was instructed to solicit 100 participants. All the interviewers have solicited participants in the two weather conditions.

The experiment was conducted on sunny and cloudy days from 10 a.m. to 12 a.m. However, precaution was taken not to conduct the experiment when it rained. The experiment was conducted when the temperature was between 18 and $22^{\circ} \mathrm{C}$, and precaution was also taken to avoid significant variation in external temperatures. This was possible because the two towns where the experiment was conducted are associated with modest variation in external temperature during the morning when the sky is cloudy. This uniformity is explained by the presence of the sea, which prevents sharp drops in external temperature. To obtain better control of the weather conditions, further pedestrians, who were not approached by the interviewers, were asked to evaluate the sky with the help of a scale ranging from 1 (cloudy) to 9 (sunny). This evaluation was done by two assistants who were not used as interviewers. Of course, in order to prevent interviewers from guessing the objective of the study, they were not present during this phase of the evaluation. We decided to perform the study with the interviewers only when the mean of this further group of pedestrian ratings was from 1 to 3 (cloudy days) or from 7 to 9 (sunny days).

At the end of the study, precaution was taken to evaluate possible suspicion of the interviewers with the real objective of the study. None of them reported weather conditions as a possible explanation.

\section{Results}

The number of participants who complied with the interviewers' survey request was the dependent variable measured in this study, and the data are presented in Table 1.

To account for the effects that the variables may have had, a 2 (participant gender $) \times 2$ (interviewer gender) $\times 2$ (weather condition) $\log$-linear analysis was applied. This technique is used instead of the traditional Pearson's independent chi-square test when more than two categorical variables exist. A main effect of the weather condition was found $\left(\chi^{2}=9.87, p=0.002, \mathrm{~V}=0.08\right.$ ) revealing that, overall, participants complied more readily on sunnier days (43.2\%) than on cloudier days (34.9\%). We found no effect of interviewer gender $\left(\chi^{2}=2.42, p=0.11, V=0.04\right)$ or participant gender $\left(\chi^{2}=1.96, p=0.11\right.$, 
Table 1 Percentage of participants who complied with the survey request according to weather condition, participant gender and interviewer gender.

\begin{tabular}{lllll}
\hline & Male interviewers & & Female interviewers \\
Male participants $(\mathrm{N}=616)$ & Sunnier days & Cloudier days & Sunnier days & Cloudier days \\
Female participants $(\mathrm{N}=768)$ & $41.5 \%$ & $31.5 \%$ & $51.8 \%$ & $40.1 \%$ \\
& $(54 / 130)$ & $(42 / 134)$ & $(88 / 170)$ & $(73 / 182)$ \\
& $42.9 \%$ & $33.3 \%$ & $42.3 \%$ & $34.1 \%$ \\
\hline
\end{tabular}

$\mathrm{V}=0.04)$. However, an interaction effect was found between interviewer gender and participant gender $\left(\chi^{2}=9.83, p=0.008\right)$ revealing that male participant complied more readily to a female interviewer than to a male interviewer whereas no difference was found with female participants. Further interaction effects showed no statistical significance.

\section{Discussion}

A greater number of participants complied with a survey request on sunny days. This effect was found both with male and female participants and with male and female. This experiment has some practical interest by showing that the response rate to a survey is clearly influenced by weather conditions. These results extend those reported in previous studies that found that sun fosters positive social relationships (Cunningham 1979). However, in the Cunningham study only tipping behavior was measured and Flynn and Greenberg (2010) failed to observe a weather effect on tipping. However in these studies, data were not controlled according to temperature or rain and people were not solicited to rate the sky as in our experiment.

Several studies have found that people reported positive mood on sunnier days (Cunningham 1979; Denissen et al. 2008; Keller et al. 2005) and it has also been found that positive mood facilitated social relationships and helping behavior (Forgas 1998; Job 1987; Rind 1997) suggesting that the effect of sun on helping is probably mediated by mood. It could be interesting in further study to evaluate the role of mood on helping behavior according to the weather conditions.

This experiment has some limitations. The interviewers were not informed about the real objective of the study and previous research on this topic. However, they may have unconsciously behaved differently according to the weather conditions. For example sunny days may affect respondent behavior through the interviewer's more positive mood. In this study, precaution was taken to control for the external temperature and not to experiment on raining days. However, further variables that could have had an influence on driver's response, are difficult to control (air humidity, wind...). 


\section{REFERENCES}

Bizman, A., Y. Yinin, B. Ronco, and T. Schachar. 1980. "Regaining Self-Esteem through Helping Behavior.The.” Journal of Psychology 105 (2): 203-9.

Cunningham, M.R. 1979. "Weather, Mood, and Helping Behavior: Quasi Experiments with the Sunshine Samaritan.” Journal of Personality and Social Psychology 37 (11): 1947-56.

Denissen, J.J.A., L. Butalid, L. Penke, and M.A.G. van Aken. 2008. "The Effects of Weather on Daily Mood: A Multilevel Approach.” Emotion 8 (5): 662-67.

Flynn, S.M., and A.E. Greenberg. 2010. "Does Weather Actually Affect Tipping? An Empirical Analysis of Time Series Data.” Personal Document. http://mpra.ub.uni-muenchen.de/25118/.

Forgas, J.P. 1997. "Affect and Strategic Communication: The Effects of Mood on the Production and Interpretation of Verbal Requests." Polish Psychological Bulletin 28 (2): 145-73.

_- - 1998. "Asking Nicely? The Effects of Mood on Responding to More or Less Polite Requests.Personality and Social." Psychology Bulletin 24 (2): 173-85.

Harris, M.B., and R.J. Smith. 1975. "Mood and Helping.” The Journal of Social Psychology 91 (2): 215-21.

Hirshleifer, D., and T. Shumway. 2003. "Good Day Sunshine: Stock Returns and the Weather." Journal of Finance 58 (3): 1009-32.

Job, S. 1987. "The Effect of Mood on Helping Behavior.” The Journal of Social Psychology 127 (4): 323-28.

Keller, M.C., B.L. Fredrickson, O. Ybarra, S. Côté, K. Johnson, J. Mikels, A. Conway, and T. Wager. 2005. "A Warm Heart and a Clear Head: The Contingent Effects of Weather on Mood and Cognition.” Psychological Science 16 (9): 724-31.

Rind, B. 1996. "Effect of Beliefs about Weather Conditions on Tipping.Journal of Applied Social Psychology" 26 (2): 137-47.

- - . 1997. "Effect of Interest Arousal on Compliance with a Request for Help.” Basic and Applied Social Psychology 19 (1): 49-59.

Rind, B., and D. Strohmetz. 2001. "Effect of Beliefs about Future Weather Conditions on Restaurant Tipping.” Journal of Applied Social Psychology 31 (10): 2160-64.

Simonsohn, U. 2007. "Clouds Make Nerds Look Good: Field Evidence of the Influence of Incidental Factors on Decision Making." Journal of Behavioral Decision Making 20 (2): 143-52.

Weyant, J. 1978. "Effects of Mood States, Costs, and Benefits of Helping." Journal of Personality and Social Psychology 36 (10): 1169-76. 